\title{
The Influence of Soil Fungi on the Sorption of Cesium and Strontium in the Soil Organic Layer
}

\author{
Prapamon Seeprasert, Minoru Yoneda, and Yoko Shimada
}

\begin{abstract}
Large quantities of cesium (Cs) and strontium (Sr) released from the Fukushima accident in $\mathbf{2 0 1 1}$ are still present in terrestrial ecosystems. This study addressed the contribution of microbial activity to the sorption of $\mathrm{Cs}$ and $\mathrm{Sr}$ into organic material, which is necessary for comparing non-sterile systems with sterile systems. The aim was to determine the contribution of microbial activity to the sorption of $\mathrm{Cs}$ and $\mathrm{Sr}$ in organic material. The complete potential of fungi to cycle $\mathrm{Cs}$ and $\mathrm{Sr}$ in the organic soil system was assessed in a series of experiments. Organic material was prepared under laboratory conditions from leaf litter to minimize the interference from competition by clay minerals. The results of an experimental system comparing biotic and abiotic systems conclusively demonstrate that soil fungi play an important role in the sorption and retention of $\mathrm{Cs}$ and $\mathrm{Sr}$. In all experiments, the retention of both elements was greater in biotic systems than in abiotic systems. Soil and saprotrophic fungi make an important contribution to the sorption of $\mathrm{Cs}$ and $\mathrm{Sr}$ in organic systems and may partly account for the strong, irreversible binding observed in biotic systems. The single strains of Fusarium sp., Trichoderma sp., and Aspergillus sp. showed increased amounts of $\mathrm{Cs}$ and $\mathrm{Sr}$ in a fixed form compared with those found in a biotic system. This finding may partly account for the high level of retention of $\mathrm{Cs}$ and $\mathrm{Sr}$ in upland organic soil, which is not satisfactorily accounted by the physicochemical process alone. It may also partly account for the strong, irreversible binding observed in biotic systems.
\end{abstract}

Index Terms - Cesium, organic soil, soil fungi, strontium.

\section{INTRODUCTION}

Large quantities of cesium (Cs) and strontium ( $\mathrm{Sr}$ ) released from the Fukushima accident in 2011 are still present in terrestrial ecosystems. The fractions of $\mathrm{Cs}$ and $\mathrm{Sr}$ linked to organic matter and microorganisms in soil may be relatively small compared with the amount bound to inorganic constituents; however, the organic layers in the soil system are more sensitive to the presence of humic acid, which can induce $\mathrm{Cs}$ and $\mathrm{Sr}$ to change into their soluble forms and be persistently available for uptake by plants [1]-[3]. Previous studies have shown that the behavior (e.g., distribution and mobility in soil) of Cs and $\mathrm{Sr}$ is significantly influenced by organic matter [4], [5]. Thus, it can be assumed that $\mathrm{Cs}$ and $\mathrm{Sr}$ are strongly retained in the top layer of organic soil [6]. For example, 40 years after the atomic bomb explosion in Nagasaki, Japan, Cs monitoring showed that $95 \%$ of the fallout was still present in the uppermost $10 \mathrm{~cm}$ of local soil [7]

Manuscript received June 21, 2015; revised August 5, 2015. This work was partially supported by the "Human Security Engineering Education Program," Graduate School of Engineering, Kyoto University.

The authors are with the Department of Environmental Engineering, Graduate School of Engineering, Kyoto University, Kyoto, Japan (e-mail: noon@ risk.env.kyoto-u.ac.jp). and that the rate of vertical migration was low [8], [9]. It can be assumed that the strong retention of $\mathrm{Cs}$ and $\mathrm{Sr}$ in the organic layer is influenced by fungal and microbial activities.

The fungal and microbial activities in the organic soil layer are likely to substantially contribute to the long-term retention of radionuclides in the organic layer [10], [11]. In the forest soil, fungi are the greatest living biomass in the decomposing organic layers. They are the primary source of enzymes necessary to degrade the litter. Griffin (1981) showed the ability of fungi to take up nutrients from the soil solution [12] Using the fungi enzymes to break down macromolecular complex, then most substances is easily to move into the cell or being bound to specific carrier molecular. Nowadays, the ability of microorganisms which includes bacteria, actinomycetes and fungi to accumulated $\mathrm{Cs}$ and $\mathrm{Sr}$ from their external environment has been largely studied. However, the mechanisms involved in the uptake and retention of $\mathrm{Cs}$ and $\mathrm{Sr}$ which is contribution of microbial activity to the sorption of $\mathrm{Cs}$ and $\mathrm{Sr}$ in organic material by fungi has been scarce. Thus, the role of soil microbiological process in the bioavailability of $\mathrm{Cs}$ and $\mathrm{Sr}$ needs to be more completely elucidated in order to predict the fate and transfer of $\mathrm{Cs}$ and $\mathrm{Sr}$ in soil. The role of microorganisms in the biogeochemical cycling of $\mathrm{Cs}$ and $\mathrm{Sr}$ can affect the soil solution by various mechanisms, both direct and indirect. For example, microorganisms can alter the soil $\mathrm{pH}$ and can act as potential ligands in the form of low-molecular-weight organic compounds with their exudates. In addition, $\mathrm{Cs}$ and $\mathrm{Sr}$ may directly attach to the cell surface or be actively taken up from the soil solution [13]-[15].

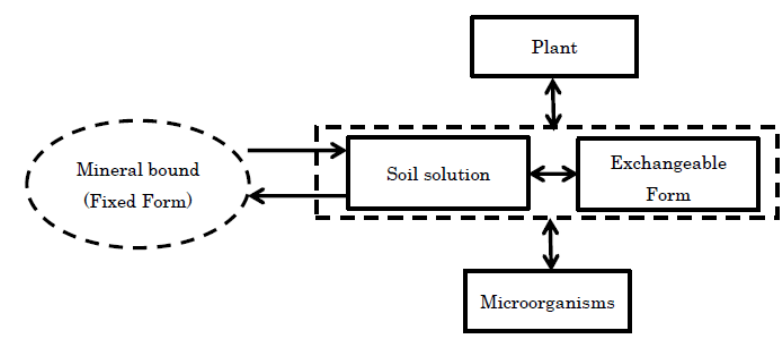

Fig. 1. A conceptual schematic summarizing Cs and Sr transfer into microorganisms and plants from soil. This figure was adapted from Avery (1996) [16].

The source of Cs and Sr in Fig. 1 is anthropogenic activities, which may be nuclear weapons testing, discharge of nuclear waste effluent, or accidental release that is deposited in soil via rainfall. $\mathrm{Cs}$ and $\mathrm{Sr}$ in soil are present in various solid components because of their binding capacity and in the soil solution. Thus, a wide range of soil properties such as $\mathrm{pH}$, the presence of smaller ions $\left(\mathrm{K}^{+}, \mathrm{Ca}^{2+}\right)$, clay content, and the amount of organic matter, including microbial or fungal activity, are known to affect the solid-solution exchange that controls the soil solution composition. In general, the organic 
fraction of soils has a larger cation exchange capacity than the inorganic soil content. It can be assumed that $\mathrm{Cs}$ and $\mathrm{Sr}$ can be taken up from soil solution into microorganisms.

A conceptual schematic summarizing Cs and Sr transfer from soil to microorganisms and plants is presented in Fig. 1.

In a previous study, the fungal retention of $\mathrm{Cs}$ and $\mathrm{Sr}$ was assessed by measuring the amounts of $\mathrm{Cs}$ and $\mathrm{Sr}$ stored in fungal cells [17]. However, it is necessary to compare nonsterile systems with sterile systems in order to assess the complete potential of fungi to cycle $\mathrm{Cs}$ and $\mathrm{Sr}$ in soil; this is described in this paper. The aim of this study was to determine the contribution of microbial activity to the sorption of Cs and $\mathrm{Sr}$ in organic material. In this study, organic material was prepared from washed leaf litter to minimize interference from inorganic components and determine the true potential of litter and fungi to accumulate both $\mathrm{Cs}$ and $\mathrm{Sr}$ in situ.

\section{PROCEDURE FOR PAPER SUBMISSION}

\section{A. Organic Material Preparation}

The organic materials used in the experiment were prepared from leaf litter collected from four areas in Takizawa Research Forest, Iwate University, Japan, during the fall of 2014. The basic characteristics of leaf litter, such as moisture content and $\mathrm{pH}$, were analyzed (Table I). The material was sorted to remove trash and washed with deionized water to reduce the interference from inorganic material. Subsequently, the leaf litter was air dried and shredded. Deionized water was then added to adjust the moisture content to $60 \%$, and the preparation was incubated at a temperature of $25^{\circ} \mathrm{C}-30^{\circ} \mathrm{C}$ for 1 month.

TABLE I: BASIC CHARACTORISTICS OF THE LEAF LITTER USED IN THIS STUDY

\begin{tabular}{|c|c|c|c|}
\hline Site & Coordinates & Moisture (\%) & $\mathrm{pH}$ \\
\hline IWT $1^{1 /}$ & $39^{\circ} 46^{\prime} 55^{\prime \prime} \mathrm{N} 141^{\circ} 9^{\prime} 22^{\prime}$ & $65.65 \pm 1.9$ & $5.11 \pm 0.02$ \\
\hline IWT $2^{2 \prime}$ & $39^{\circ} 46^{\prime} 33^{\prime \prime} \mathrm{N} 141^{\circ} 9^{\prime} 25^{\prime}$ & $62.16 \pm 0.59$ & $5.39 \pm 0.0 .8$ \\
\hline IWT $3^{2 /}$ & $39^{\circ} 46^{\prime} 33^{\prime \prime} \mathrm{N} 141^{\circ} 9^{\prime} 10^{\prime}$ & $46.05 \pm 2.37$ & $5.73 \pm 0.02$ \\
\hline IWT $4^{1 /}$ & $39^{\circ} 46^{\prime} 53^{\prime \prime} \mathrm{N} 141^{\circ} 9^{\prime} 1^{\prime}$ & $76.48 \pm 2.68$ & $5.48 \pm 0.03$ \\
\hline
\end{tabular}

\section{B. Soil Extraction Solution (SES) Preparation}

SES was prepared using soil from the O layer from all the areas to provide inoculum for all experiments. A sample of $5 \mathrm{~g}$ soil dry weight equivalent was added to $50 \mathrm{ml}$ of sterile distilled water (SDW) in a sterile centrifuge tube. The tube was shaken for $1 \mathrm{~h}$ and left to stand for $30 \mathrm{~min}$. The supernatant was used as inoculum for biotic systems.

\section{System Preparation}

Single fungal cultures of Fusarium sp., Trichoderma sp., and Aspergillus sp. were obtained by isolation from soil [17]. After incubation for 7 days, each cell mat was washed to stop cell growth using SDW and subsequently resuspended in SDW. Samples of organic material measuring $5 \mathrm{~g}$ dry weight equivalent were set up as systems, with separate systems for abiotic and biotic processes. The biotic samples were reinoculated with $5 \mathrm{ml}$ of SES. Separate systems were prepared for the three fungal genera used in this study: Fusarium sp., Trichoderma sp., and Aspergillus sp. For the abiotic setup, the system was amended with an equal quantity of SDW and sterilized by autoclaving. In total, $40 \mu \mathrm{g}$ of sterile $\mathrm{Cs}$ and $\mathrm{Sr}$ solution was added to $5 \mathrm{~g}$ of the organic material sample. SDW was added to adjust the moisture content to $70 \%-80 \%$ before sealing with a cap to avoid moisture loss and prevent contamination. Two replicates of each system were prepared. After 30 days, the subsamples of the systems were collected for measuring $\mathrm{Cs}$ and $\mathrm{Sr}$ bioavailability.

\section{Sample Analysis}

After incubation, approximately $1 \mathrm{~g}$ dry weight equivalent of organic material was removed from systems. The samples were then flushed with $20 \mathrm{ml} \mathrm{SDW} \mathrm{(pH} \mathrm{6.3-7.3)} \mathrm{for} 24 \mathrm{~h}$ under shaker conditions. Following this, $0.1 \mathrm{mg} / \mathrm{l}$ of cation mix contain $\left(\mathrm{K}^{+}, \mathrm{Ca}^{2+}\right.$, and $\left.\mathrm{Mg}^{2+}\right)$ was used as an extractant to determine the more tightly bound fractions of $\mathrm{Cs}$ and $\mathrm{Sr}$. The amounts of $\mathrm{Cs}$ and $\mathrm{Sr}$ in the solution were measured by inductively coupled plasma mass spectrometry (ICP-MS; XSeries 2, Thermo Scientific). Sample preparation followed the standard methods ISO17294-2 and EPA 6020a [18], and the percentage of spiked elements extracted was calculated. The total amount extractable represents the exchangeable and potentially bioavailable fraction of $\mathrm{Cs}$ and $\mathrm{Sr}$ spiked.

\section{RESULTS AND DISCUSSION}

\section{A. Effects of Soil Fungi}

To interpret the experimental results, two sets of observations were used to infer whether soil microorganisms play an important role in $\mathrm{Cs}$ and $\mathrm{Sr}$ sorption and retention. The experimental data consisted of a comparison between the amounts of each element: $\mathrm{Cs}$ and $\mathrm{Sr}$ were extracted using distilled water following the incubation period (1 month). Fig. 2 shows that $27 \%-50 \%$ of Cs spiked into the abiotic systems was extracted by the distilled water, whereas only $8 \%-24 \%$ of Cs was extracted from the biotic systems that were reinoculated with SES. The amount of $\mathrm{Sr}$ extracted was less than that of Cs: $10 \%-20 \%$ for the abiotic systems, and only $5 \%-10 \%$ for the biotic systems.

The results showed the same trend for all locations: ITW1 showed a larger amount of $\mathrm{Ca}$ and $\mathrm{Sr}$ extracted than IWT3. Water flushing removed more $\mathrm{Cs}$ than $\mathrm{Sr}$. A previous study that investigated the extraction of $\mathrm{Cs}$ and $\mathrm{Sr}$ as radioactive isotopes, ${ }^{137} \mathrm{Cs}$ and ${ }^{85} \mathrm{Sr}$ also showed the same trend of result in both abiotic systems, followed by autoclaving and using a fungicide such as streptomycin [19]. In this study, we also used a different extractant, a mixed cation solution containing $1 \mathrm{mg} / \mathrm{l}$ of $\mathrm{K}^{+}, \mathrm{Ca}^{2+}$, and $\mathrm{Mg}^{2+}$, to determine the levels of exchangeable $\mathrm{Cs}^{+}$and $\mathrm{Sr}^{2+}$ in the organic material for the abiotic and biotic systems. The results are shown in Fig. 3 .

The amounts of Cs bound to organic material extracted by distilled water from the abiotic treatment were $50 \%, 48 \%$, $28 \%$, and $40 \%$ of the initial Cs concentration. These values are higher than those for the mixed cation solution, which were $31 \%, 30 \%, 23 \%$, and $27 \%$ of the initial Cs concentration for the locations IWT1-IWT4, respectively. However, the results for biotic treatment show that the percentage of $\mathrm{Cs}$ extracted using the mixed cation solution decreased to $14 \%-18 \%$ of the initial Cs concentration. These results 
indicate that the sorption of Cs was weak, whereas the sorption of Sr was much stronger, which corresponds with that observed previously; $\mathrm{Sr}$ is mostly bound by organic material, whereas Cs is strongly bound by clay minerals in soil [20], [21].
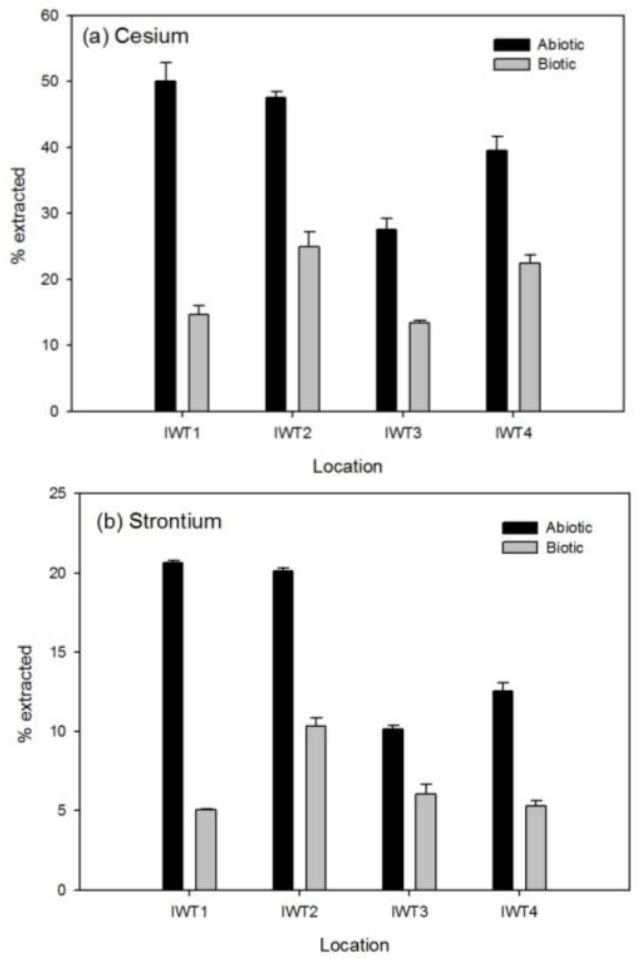

Fig. 2. Percentages of (a) Cs and (b) Sr extracted using distilled water from organic material in abiotic and biotic systems for four different soil locations.

Results showed that Cs is more strongly bound in the presence of soil microorganisms in the biotic system than in the abiotic system, indicating that the microorganisms associated with Cs accounted for a significant proportion of $\mathrm{Cs}$ in the contaminated upland soil. This is thought to be because of microbial activity, which can accumulate Cs though the active transport of monovalent ions such as $\mathrm{K}^{+}$and $\mathrm{NH}_{4}^{+}$[10], [16]. This experiment indicates that bacterial and fungal microbiota that was re-inoculated from SES can enhance the retention of Cs, particularly in the organic layer.
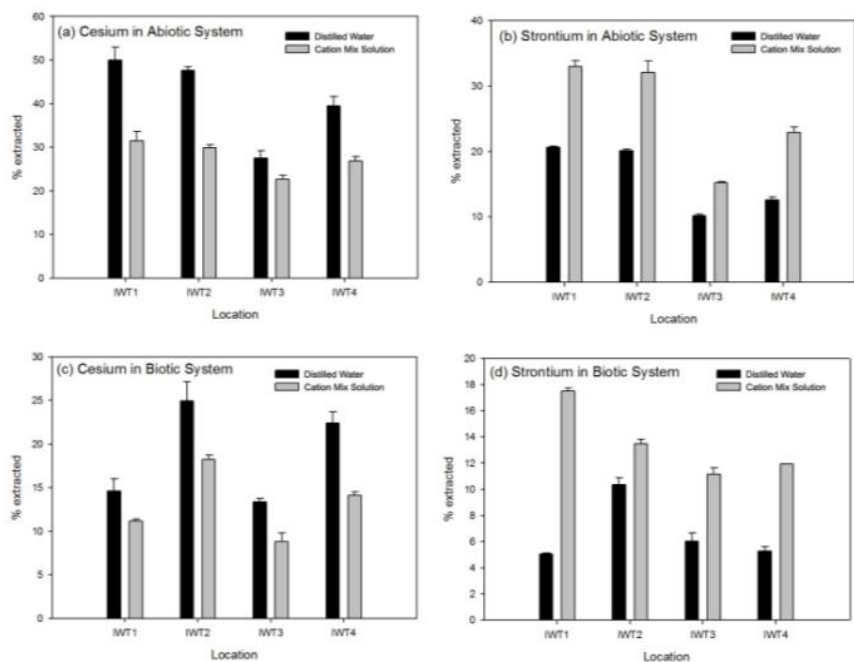

Fig. 3. Percentage of (a), (c) Cs and (b), (d) Sr extracted using different solutions from organic material in abiotic (a), (b) and (c), (d) biotic systems for four different soil locations.

\section{B. Effects of Single Fungal Culture}

These experiments were performed to determine the importance of saprotrophic fungal cultures for the sorption of $\mathrm{Cs}$ and $\mathrm{Sr}$ in the organic soil system. The results are shown in Fig. 4. As in the previous study [17], three soil fungal cultures were isolated from a soil sample, confirming that these organisms are present in the biotic organic layer. The inoculation of the organic material with each of the three soil fungal strains increased the sorption of both $\mathrm{Cs}$ and $\mathrm{Sr}$, as demonstrated by the amount of element remaining after extraction compared with that in the abiotic system.
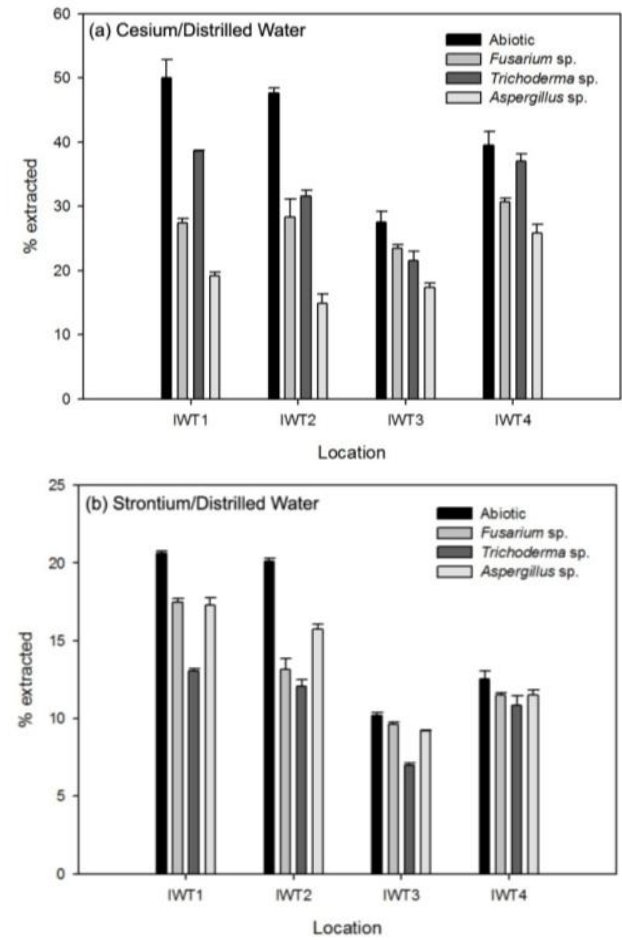

Fig. 4. Percentages of (a) Cs and (b) Sr extracted by distilled water from organic material in biotic systems inoculated by single fungal cultures for four different soil locations.

In the system inoculated with single fungal cultures, approximately $18 \%-39 \%$ of the initial Cs was extracted, whereas in the abiotic system, $28 \%-50 \%$ of the initial Cs was extracted. The system inoculated with Aspergillus sp. showed a slightly higher ability to retain $\mathrm{Cs}$ than those inoculated with Fusarium sp. and Trichoderma sp. However, for $\mathrm{Sr}$ in biotic systems, only $7 \%-17 \%$ of the initial $\mathrm{Sr}$ was extracted, whereas for abiotic systems, approximately $10 \%-20 \%$ of the initial $\mathrm{Sr}$ was extracted. In contrast, the system inoculated with Trichoderma sp. showed a slightly higher ability to retain Sr than those inoculated with Fusarium sp. and Aspergillus sp. From this limited analysis, biosorption by fungal cells appears to be species specific, depending on the components of the fungal cell walls that provide binding sites for elements [22]. The results of $\mathrm{Cs}$ and $\mathrm{Sr}$ extraction using the mixed cation solution from single fungal cultures are illustrated in Fig. 5.

The results of extraction using the mixed cation solution (Fig. 5) showed that biotic systems initially retained a higher proportion of each element. Dighton et al. (1991) estimated the accumulation of $\mathrm{Cs}$ by pure cultures of soil fungi and demonstrated that all studied strains were able to immobilize Cs. Efflux studies showed that more than $40 \%$ of the Cs was bound within hyphae [10]. The Fusarium sp. culture used in 
this study was similar to that used in a previous study [19]. In this study, fungal retention increased the amount of non-extractable $\mathrm{Cs}$ and $\mathrm{Sr}$ in comparison with the abiotic system. In batch experiments using single fungal culture solutions, retention was enhanced in systems inoculated with Aspergillus sp. for Cs and Trichoderma sp. for Sr compared with abiotic systems. Clint et al. (1991) demonstrated that pure cultures of various saprotrophic and mycorrhizal fungi can take up Cs [23]; in that study, there was no indication of permanent binding of elements. The experimental results from two fungal cultures, Aspergillus sp. and Trichoderma sp. demonstrated that the majority of biosorbed $\mathrm{Cs}$ and $\mathrm{Sr}$ within organic material remained in an exchangeable form. We infer that these $\mathrm{Cs}$ and $\mathrm{Sr}$ are available for uptake by plants.
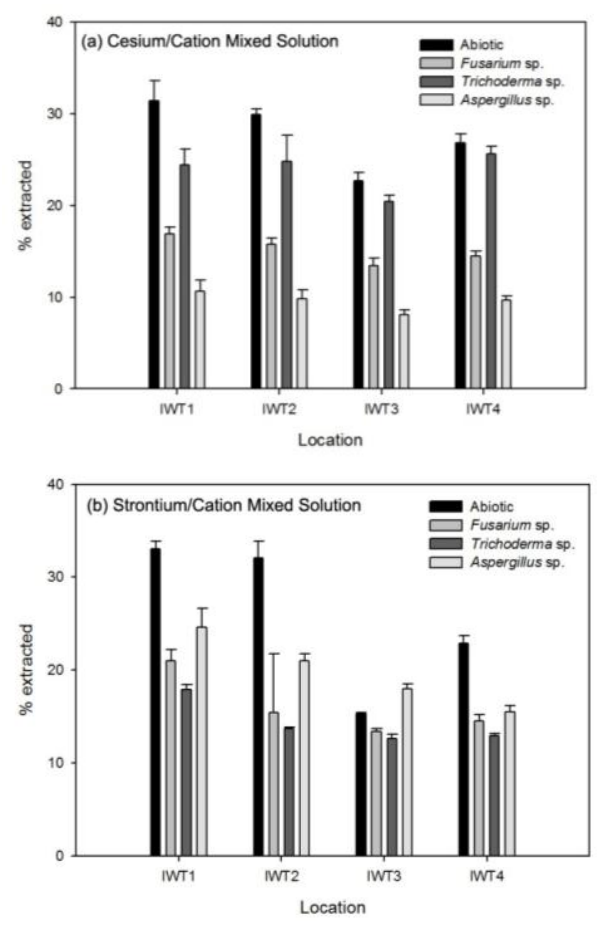

Fig. 5. Percentages of (a) Cs and (b) Sr extracted using mixed cation solution from organic material in biotic systems inoculated with single fungal cultures for four different soil locations

\section{CONCLUSION}

The aim of this study was to determine the contribution of microbial activity to the sorption of $\mathrm{Cs}$ and $\mathrm{Sr}$ into organic material, which is necessary for comparing nonsterile systems with sterile systems. This study highlights the need to develop a new experimental approach to characterize the maximum potential of soil fungi to accumulate $\mathrm{Cs}$ and $\mathrm{Sr}$ in soil. The results in an experimental system comparing biotic and abiotic systems conclusively demonstrate that soil fungi play an important role in the sorption and retention of Cs and Sr. In all experiments, the retention of both elements was greater in biotic systems than in abiotic systems. Soil and saprotrophic fungi make an important contribution to the sorption of $\mathrm{Cs}$ and $\mathrm{Sr}$ in organic systems and may partly account for the strong, irreversible binding observed in biotic systems. This finding may account for the high level of radioactive Cs and $\mathrm{Sr}$ retention in the in situ upland soil organic layer, which cannot be satisfactorily accounted for by physicochemical processes.

\section{ACKNOWLEDGMENT}

This work was partially supported by the "Human Security Engineering Education Program," Graduate School of Engineering, Kyoto University. The authors wish to thank the reviewers for their relevant and helpful comments. I would like to express my sincere thanks to Ikegami sensei and Office of Agriculture Technology, Forest management groups, Iwate University for their kind support during sampling in Takizawa Forest.

\section{REFERENCES}

[1] B. J. Howard, N. A. Beresford, L. Burraw, P. V. Shaw, and E. J. Curtis, "A comparison of caesium 137 and 134 activity in sheep remaining on upland areas contaminated by chernobyl fallout with those removed to less active lowland pasture," Journal of the Society of Radiological Protection, vol. 72, pp. 71-73, 1987.

[2] J. P. Absalom, S. D. Young, and N. J. Crout, "Radiocesium fixation dynamics - Measurement in six Cumbrian soil," European Journal of Soil Science, vol. 463, pp. 461-469, 1995.

[3] A. L. Sanchez, N. R. Parekh, B. A. Dodd, and P. Ineson, "Microbial component of radiocaesium retention in highly organic soils," Soil Biology and Biochemistry, vol. 32, pp. 2091-2094, 2000.

[4] D. R. Brookshaw, R. A. Patrick, J. R. Lloyd, and D. J. Vaughan, "Microbial effect on mineral-radionuclide interactions and radionuclide solid-phase capture processes," Mineralogical Magazine, vol. 76, no. 3, pp. 777-806, 2012.

[5] W. Ruhm, S. Yoshida, Y. Marumatsu, M. Steiner, and E. Wirth, "Distribution pattens for stable 133Cs and their implication with respect to the long-term fate of radioactive $134 \mathrm{Cs}$ and $137 \mathrm{Cs}$ in a semi-natural ecosystem," Journal of Environmental Radioactivity, vol. 45, pp. 253-270, 1999.

[6] S. Yoshida, Y. Marumatsu, A. M. Dvornik, and I. Linkov, "Equilibrium of radiocesium with stable cesium within the biological cycle of contaminated forest ecosystems," Journal of Environmental Radioactivity, vol. 75, no. 3, pp. 301-313, 2004.

[7] Y. Mahara, "Storage and migration of fallout strontium-90 and cesium-137 for over 40 years in the surface soil of Nagasaki," Journal of Environmental Quality, vol. 22, no. 4, pp. 722-730, 1993.

[8] K. Rosen, I. Oborn, and H. Lonsjo, "Migration of radiocaesium in Swedish soil profiles after the Chernobyl accident," Journal of Environmental Radioactivity, vol. 46, pp. 45-66, 1999.

[9] L. Newsome, K. Morris, and J. R. Lloyd, "The biogeochemistry and bioremediation of uranium and other priority radionuclides," Chemical Geology, vol. 363, pp. 164-184, 2014.

[10] J. Dighton, G. M. Clint, and J. Poskitt, "Uptake and accumulation of Cs-137 by upland grassland soil fungi: a potential pool of Cs immobilization," Mycological Research, vol. 95, pp. 1052-1056, 1991.

[11] M. Steiner, I. Linkov, and S. Yoshida, "The role of fungi in the transfer and cycling of radionuclides in forest ecosystems," Journal of Environment Radioactivity, vol. 58, pp. 217-241, 2002.

[12] D. H. Griffin, Fungal Physiology, New York: John Wiley \& Son, 1981

[13] C. Tamponnet, A. G. Martin, M. A. Gonze, N. Parekh, R. Vallejo, and T. Y. Sauras, "An over view of BORIS: Bioavailability of radionuclides in soils," Journal of Environmental Radioactivity, vol. 99, pp. 820-830, 2008.

[14] C. Tamponnet, C. Plassard, N. Parekh, and A. Sanchez, "Impact of micro-organisms on the fate of radionuclides in rhizospheric soils," in F. Brechignac and B. Howard, Eds., Radioactive Pollutants: Impact on the Environment, pp. 175-185, Les Ulis: EDP Science, 2001.

[15] J. R. Lloyd and J. C. Renshaw, "Bioremediation of radioactive waste: Radionuclide microbe interactions in laboratory and field scale studies," Current Opinion in Biotechnology, pp. 254-260, 2005.

[16] S. V. Avery, "Fate of caesium in the environment: distribution between the abiotic and biotic components of aquatic and terrestrial ecosystems," Journal of Environmental Radioactivity, vol. 30, pp. 139-171, 1996.

[17] P. Seeprasert, M. Yoneda, Y Shimada, and Y. Matsui, "Tolerance and accumulation of cesium and strontium in saprotrophic fungi," Journal of Physics: Conference Series, vol. 611, 2015.

[18] J. V. Henk, Determination of Elements by ICP-AES and ICP-MS, National Institute for Public Health and the Environment," 2003.

[19] N. R. Parekh, J. M. Poskitt, B. A. Dodd, E. D. Potter, and A. Sanchez, "Soil microorganisms determine the sorption of radionuclides within 
organic soil system," Journal of Environmental Radioactivity, vol. 99, pp. 841-852, 2008.

[20] S. Forsberg, K. Rosen, and F. Brechignac, "Chemical availability of $137 \mathrm{Cs}$ and $90 \mathrm{Sr}$ in undistributed lysimeter soils maintained under controlled and close-to-real conditions," Journal of Environmental Radioactivity, vol. 54, 253-265, 2001.

[21] S. Lofts, E.W. Tipping, A. L. Sanchez, and B. A. Dodd, "Modeling the role of humic acid in radiocaesium distribution in a British upland pea soil, “Journal of Environmental Radioactivity, vol. 61, pp. 133-147, 2002.

[22] J. Tobin, C. White, and G. M. Gadd, "Fungal accumulation of toxic metals and application to environmental technology," Journal of Industrial Microbiology, vol. 13, pp. 126-130, 1994.

[23] G. Clint, A. Harrison, and D. Howard, "The release of Caesium 137 from plant litters and effects of microbial activity on this process," in G Desmet, P. Nassimbini, and M. Belli, Eds., Transfer of Radionuclides in Natural and Semi-natural Environments, Elsevier, 1991.

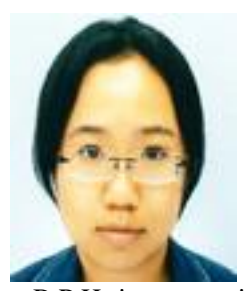

Prapamon Seeprasert was born in 1986 in Samutprakarn, Thailand. In 2009, she received her B.Sc. in environmental science from Kasetsart University, Thailand. In 2012, she received her M.Sc in environmental technology and management from the same university with a thesis focused on evaluating cadmium uptake in rice using neutron activating analysis. In the same year, she also received a B.P.H. in occupational health and safety form Sukhothai Thammathirat Open University, Thailand. Now, She is currently a third years Ph.D student in environmental engineering at Kyoto University, Her thesis is focused on the influence of microorganism and their interaction to elements e.g. Cs and $\mathrm{Sr}$ in the soil under Professor Minoru Yoneda.

Minoru Yoneda is a professor at Kyoto University. He works on clarification of dynamism and exposure-dosage assessments of medium-boiling-point organic chemical substances in general living environments to evaluate their risk for the public. He also aims to clarify the mechanisms of urban soil contamination with traces of harmful substances such as heavy metals.

Yoko Shimada is an associate professor belonging to risk assessment analysis laboratory, Kyoto University. Her research topics were focused on human health is threatened by various types of environmental risks such as radioactive substances. 